\title{
Modeling and Simulation of Ultrahigh Sensitive AIGaN/AIN/GaN HEMT based Hydrogen gas detector with low detection limit
}

\author{
Arathy Varghese, Member, IEEE, Abdalla Eblabla, and Khaled Elgaid, Senior Member, IEEE
}

\begin{abstract}
Presented through this work is a steady state analytical model of the GaN HEMT based gas detector. GaN with high chemical and thermal stability provides promises for detectors in hazardous environments. However, HEMT sensor resolution must be improved to develop high precision gas sensors for automotive and space applications. The proposed model aids in systematical study of the sensor performance and prediction of sensitivities. The linear relation of threshold voltage shift at thermal equilibrium is used in predicting the sensor response. Numerical model for the reaction rates and the electrical dipole at the adsorption sites at the surface and metal/semiconductor interface have been developed and the sensor performance is analyzed for various gas concentrations. The validation of the model has been achieved through surface and interfacial charge adsorption-based gate electrode work function, Schottky barrier, 2DEG and threshold voltage deduction using MATLAB and SILVACO ATLAS TCAD. Further the applicability of $\mathrm{g}_{\mathrm{d}}$ (channel conductance) as gas sensing metric is also presented. With high lo and $\mathrm{gd}_{\mathrm{d}}$ percentile sensitivities of $118.5 \%$ and $92 \%$ for $10 \mathrm{ppm}$ hydrogen concentration. The sensor shows capability for detection in sub-ppm levels by exhibiting a response of $0.043 \%$ for $0.01 \mathrm{ppm}(10 \mathrm{ppb})$ hydrogen concentration. The detection limit of the sensor $(1 \%$ sensitivity) presented here is $169 \mathrm{ppb}$ and the device current increases by $34.2 \mu \mathrm{A}$ for $1 \mathrm{ppb}$ hydrogen concentration.

Index Terms_-AIGaN/GaN HEMT; gas sensor; numerical model; hydrogen; TCAD.
\end{abstract}

\section{INTRODUCTION}

$\mathrm{H}$ YDROGEN gas sensors based on GaN based devices such as diodes and HEMTs have gained huge research attention recently for automobile, pollution control and space applications [1-3]. In this emerging era of space travel, automated vehicles, rocket reuse, supersonic aircrafts, and efforts towards becoming an interplanetary species, rugged sensors are going to play a vital role. Wide band gap of GaN provides the HEMT based sensors capability to withstand high temperatures and provide stable operations in harsh environments makes them suitable for application in exhaust diagnosis and emission detection in industrial processes [4]. HEMTs are seen to show high sensitivities for detection of various gases and can be integrated with high temperature and high-power electronics on a single chip [5-8]. The sensors developed till date are not adequate for continuous monitoring systems due to huge response times and lower resolution. Higher sensitivities are achieved in sensors at the cost of lower detection limits. The GaN based sensors though provide higher

Arathy Varghese, Abdalla Eblabla, and Khaled Elgaid are with the School of Engineering, Cardiff University, United Kingdom CF24 3AA. (Corresponding author: VargheseA@cardiff.ac.uk) sensitivities than the metal oxide-based systems, are found to lag behind in terms of detection limits. $\mathrm{AlGaN} / \mathrm{GaN}$ heterostructures promises great potential for development of sensors due to the highly sensitive 2DEG (Two-Dimensional Electron Gas) at the hetero interface which is highly sensitive to variation in surface charges/potential [9]. The advantages of using GaN HEMTs as gas sensors include: higher detection levels, beyond the theoretical limits and sensitivity control through gate bias. In spite, of all these advantages and research happening worldwide, till date there have not been a sensor developed that achieves low detection limits and fast responses guaranteed by the $\mathrm{AlGaN} / \mathrm{GaN}$ heterostructure. Systematic analysis of the device and its sensing behavior is important to develop sensors with high precision. Physics based analytical model are used in designing high resolution chemical and bioHEMTs [10-13]. However, till date there are no models developed that accounts for the gas sensing behavior of AlGaN/GaN HEMTs.

This work proposes a model for gas detection process involving gas adsorption/absorption at the sensing surface and sensor 
interface, formation of dipole layer at the interface which leads to a shift in the work function leading to an effective variation in the Schottky barrier height [14-16]. Even though hydrogen sensing (for application specificity) has been analytically modelled and simulated using TCAD (Technology Computer Aided Design) here, the model developed is not just limited to hydrogen, this can be employed in designing devices for any other gas detections. Hydrogen gas finds wide range of application as a clean fuel in industries, rocket propellers, transportation, generation of power, etc. This colorless and odorless gas is highly inflammable and elevated concentrations can lead to explosions [17-19]. This necessitates early detection, a wide variety of semiconductor metal oxides such as $\mathrm{WO}_{3}$ [20], $\mathrm{SnO}_{2}$ [21], $\mathrm{ZnO}$ [22] based devices are used in detection however they are found unsuitable for application at elevated temperatures and hazardous conditions. GaN based devices can overcome these limitations due to its superior material properties such as high chemical and thermal stabilities coupled with high frequency operation leading to faster responses and higher sensitivities due to presence of 2DEG. Till date, there are no optimized GaN HEMT gas sensor designs proposed that achieves large sensitivities without compromising the detection limits. To come up with the best possible sensor design, developing an analytical model that can aid in design development is utmost essential. Presented through this work is an analytical model for the $\mathrm{AlGaN} / \mathrm{GaN}$ HEMT based gas sensor and sensitivity analysis of an AlGaN/GaN HEMT design including a thin a spacer layer to improve drain current, $I_{D}$, and transconductance $g_{m}$ and thereby enhancing the device sensitivity. The use of this model will be helpful to the design engineers to overcome time, cost and process overheads during development of GaN HEMT based gas sensors.

\section{DEVICE PARAMETERS}

Gas sensing performance of an AlGaN/GaN HEMT with a thin AlN spacer enhancing the device performance [23] in terms of $\mathrm{ON}$ current and device transconductance is demonstrated through analytical model and simulation-based performance evaluation. The cross-section schematic of the $\mathrm{Pd}$ gated $\mathrm{AlGaN} / \mathrm{AlN} / \mathrm{GaN}$ HEMT sensor proposed is presented in Fig. 1. The mole fraction of $\mathrm{Al}$ in $\mathrm{AlGaN}$ is 0.23 [10, 23].

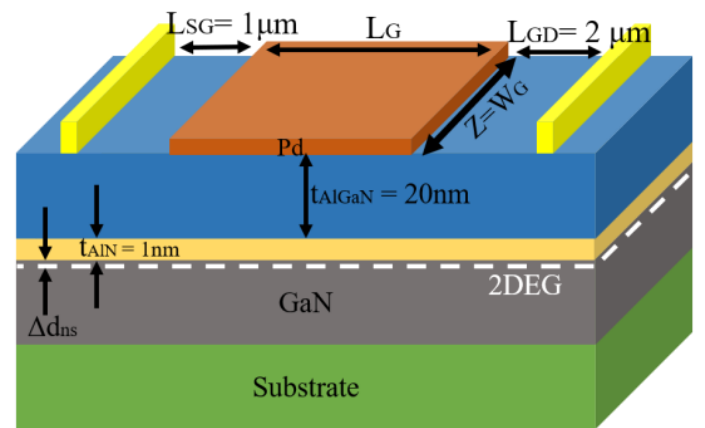

Fig. 1. Cross sectional schematic of AIGaN/AIN/GaN HEMT

The schematic representation of gas sensing phenomena at the device gate and the band diagram showing the gas adsorption and 2DEG variation at the hetero interface is shown in Fig. 2 (a) and (b) respectively. The parameters, models and device dimensions used in the simulation and model are presented in the appendix. The device dimensions are chosen based on the experimental results presented in $[10,11,23,24]$, the gate to drain spacing is kept twice the source to gate spacing. The design has been kept simple with minimum feature size used is $1 \mu \mathrm{m}$, the proposed gas sensor can be fabricated using optical lithography and using a five-level mask.

The dipole formation is simulated as formation of a very thin insulative electric double layer with permittivity of 2.25 [25, 26]. The gas adsorption at the surface/interface is simulated through an effective change in the work-function of gate metal with respect to the concentration of gas reaching the surface. The area at the gate surface is defined as an insulator with permittivity of air and having charge concentrations corresponding to hydrogen gas concentration varying from few ppt to $100 \mathrm{ppm}$. This leads to a variation in the Schottky barrier height at the gate interface. The gate work function used initially is $5.22 \mathrm{eV}(\mathrm{Pd})$ and the source and drain are simulated with an effective work function of $4 \mathrm{eV}(\mathrm{Ti} / \mathrm{Al} / \mathrm{Ni} / \mathrm{Au})$. For model development, the basic drain current model has been used. The parameters used in modeling are explained in detail in [10]. GaN HEMT sensors have been modeled for biodetections and the device current can be modelled using the basic equation: [10,11]

$I_{D}=e \times n_{s} \times Z \times v(x)$

Where, $e$ is the electron charge, $n_{s}$ the 2DEG density, $Z$ the channel width and $v(x)$ the electron drift velocity[19]. The device 2DEG density can be described as:

$n_{S}=\frac{\epsilon_{A l G a N}(m)}{d} \times\left(V_{G S}-\left(\phi_{S}+\frac{E_{F}-\Delta E_{c e f f}}{e}+V_{c h}(x)\right)\right)$

Where, $\epsilon_{\text {AlGaN }}(m)$ is the permittivity of AlGaN barrier, $d$ is the effective distance of the 2DEG from the sensing gate, $V_{c h}(x)$ is the channel potential at distance $\mathrm{x}$ from the channel, $E_{F}$ is the fermi level and $\Delta E_{c e f f}$ is the effective change in the conduction band offset at the hetero interface [10, 23]. The drain current in equation (1) can be expanded as:

$I_{D}=e \times \frac{\epsilon_{A l G a N}}{t_{A l G a N}+t_{A l N}+\Delta d_{n S}+r_{g}}\left(V_{G S}-\left(\emptyset_{S}+\right.\right.$
$\left.\left.\frac{E_{F}-\left(\Delta E_{C A l G a N}(m)+\frac{q^{2}}{\epsilon_{A l G a N}(m)} \sigma_{A l N}^{2} t_{A l N}\right)}{e}\right)\right) Z \frac{v_{S} E(x)}{\sqrt{E^{2}(x)+\left(\frac{v_{S}}{\mu}\right)^{2}}}$

Where $t_{A l G a N}, t_{A l N}, \Delta d_{n s}$, and $r_{g}$ are the thickness of barrier layer, spacer layer, 2DEG separation from the hetero interface and the roughness of the metal respectively. $\emptyset_{s}, \mu, v_{s}$ and $E(x)$ are the Schottky barrier height, low field mobility, saturation velocity and electric field component in the channel respectively. $\sigma_{A l N}$ is the polarization based charge density in the AlN spacer layer. The gas sensing mechanism used in modeling and simulation based approaches are presented in Fig. 2(c) and (d). Prior to sensitivity analysis the mathematical model and the 
simulation models are compared through drain current analysis at $\mathrm{V}_{\mathrm{DS}}=10 \mathrm{~V}$ using MATLAB 2015a and SILVACO ATLAS TCAD. The results shown perfect agreement as shown in Fig 1 (e) thereby proving the accuracy of the analytical model calibration and vice versa (validating the models used in simulation. All the simulations are performed with a mesh width of $100 \mu \mathrm{m}$ leading to normalized current outputs in amperes. Drain current and transconductance are the two important performance metrics of a GaN HEMT from the sensor point of view [10]. The device presented here even without any kind of intentional doping gives high drain current as presented in Fig. 2 (e) and good sensitivity is ensured from the steep subthreshold slope. The use of AlN interlayer and optimized barrier thickness and $\mathrm{Al}$ concentration enhances the device transconductance.

\section{GAS SENSING MODEL}

Hydrogen gas, under normal environmental conditions is an aggregation of hydrogen molecules. Hydrogen molecule comprises of two hydrogen atoms. The atomic mass of hydrogen is $1.008 \mathrm{~g} / \mathrm{mol}$ (molecular mass $=2.016 \mathrm{~g} / \mathrm{mol}$ ) which makes hydrogen gas the lightest of all gases with fastest diffusion rates due to high velocities. For physical detection of this gas using semiconductor-based devices, catalytic metals (such as Pt, Pd) are employed. This work demonstrates use of Pd based sensing gate in AlGaN/GaN HEMT to detect hydrogen gas. The surface adsorption of Hydrogen molecules at the sensing Pd gate can be modeled as: [27, 28].
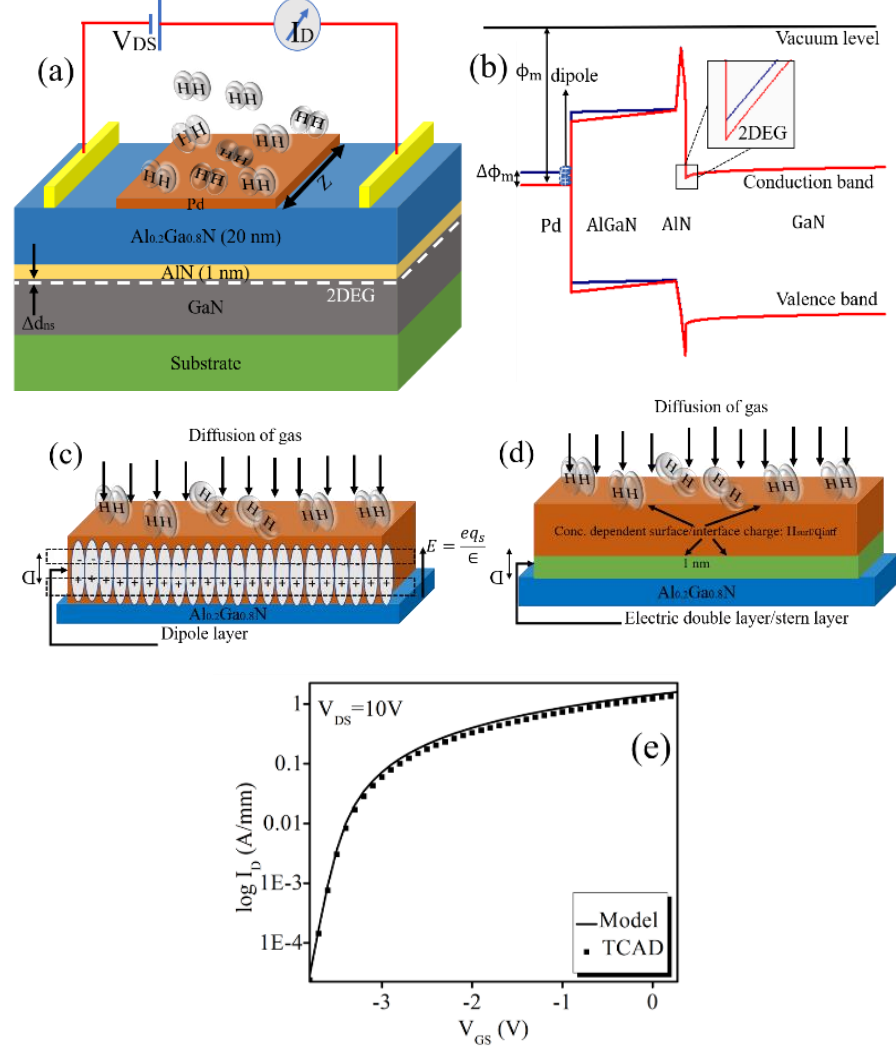

Fig.2 (a) HEMT gas sensor schematic, and (b) Energy band diagram, (c). capacitor model for the HEMT gas sensor showing formation of dipole layer at the AIGaN/Pd interface, (d). TCAD simulation approach for the electric double layer formation and sensitivity analysis, (e). Calibration and validation of model through comparison with simulation results.
$H_{2}+2 \ddot{\Theta} \leftrightharpoons 2 H . \ddot{\theta}$

Where $\ddot{\theta}$ represents the Pd surface adsorption sites. Let $K$ and $K$ ' be the forward and reverse reaction rates. The nonequilibrium constant of this reaction $(€)$ can be described as:

$€=\frac{K}{K^{\prime}}$

Similarly, the reaction at the metal/semiconductor interface can be modeled as:

$H . \ddot{\theta}+\ddot{\theta}^{\prime} \leftrightharpoons H \ddot{\theta}^{\prime}+\ddot{\theta}$

Where $\ddot{\theta}^{\prime}$ represents the adsorption sites at the metal/semiconductor interface. Let the reaction rates be $\mathrm{Q}$ and Q', the non-equilibrium constant here can be evaluated as:

$€^{\prime}=\frac{Q}{Q^{\prime}}$

Let $\mathrm{H}_{\text {surf }}$ and $\mathrm{H}_{\text {intf }}$ be the density of $\mathrm{H}$ atoms at reaching the surface and the metal/semiconductor interface adsorption sites. $\mathrm{H}_{\text {surf }}$ values for gas concentrations are summarized in Table. I. If the vacant adsorption sites on the surface $\left(\mathrm{A}_{\text {surf }}\right)$ and interface $\left(\mathrm{A}_{\text {intf }}\right)$ is equivalent to the number of $\mathrm{H}$ atoms, then the reaction becomes ideal limiting reaction and the device gives maximum performance. In physical detection, the device can give maximum performance and lead to limiting reaction is when

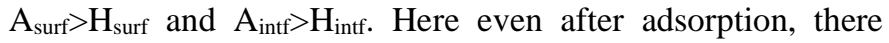
would be vacant sites left on the sensing surface and the metal/semiconductor interface. Let the density of vacant states be $V_{\text {surf }}$ and $V_{\text {intf. The }}$ Thuilibrium reaction rate can now be written as [18]:

$$
\begin{aligned}
& \theta=\frac{q_{s}}{V_{\text {intf }}}=\mathrm{\kappa} \sqrt{P}, \text { where } \mathrm{k}=€^{\prime} \\
& q_{s}=A_{\text {intf }}-V_{\text {intf }}
\end{aligned}
$$

TABLE. I

EVALUATION OF HSURF FOR VARIOUS GAS CONCENTRATION

\begin{tabular}{|c|c|c|c|}
\hline $\begin{array}{c}\text { Conc. } \\
(\mathrm{ppm})\end{array}$ & $\begin{array}{c}\text { Conc. } \\
(\mathrm{g} / \mathrm{l})\end{array}$ & $\begin{array}{c}\text { Molar conc. } \\
\text { Conc./Molecular } \\
\text { mass }(\mathrm{M} / \mathrm{l})\end{array}$ & $\begin{array}{c}\mathrm{H}_{\text {surf }}=\mathrm{qH} \text { x Molar conc. } \\
\text { x Avogadro number } \\
\left(/ 0.0011 \text { or } / \mathrm{cm}^{3}\right)\end{array}$ \\
\hline 1 & 0.001 & $4.96 \times 10^{-4}$ & $5.9748 \times 10^{17}$ \\
\hline 2 & 0.002 & $9.92 \times 10^{-4}$ & $1.1949 \times 10^{18}$ \\
\hline 5 & 0.005 & $2.48 \times 10^{-3}$ & $2.9874 \times 10^{18}$ \\
\hline 10 & 0.01 & $4.96 \times 10^{-3}$ & $5.9748 \times 10^{19}$ \\
\hline 20 & 0.02 & $9.92 \times 10^{-3}$ & $1.1949 \times 10^{19}$ \\
\hline
\end{tabular}

Molecular mass $=2.016 \mathrm{~g} / \mathrm{mol}, \mathrm{q}_{\mathrm{H}}=2$ (no: of atoms/proton charge) Avogadro number $=6.023 \times 10^{23}$

Where $\theta$ is the coverage and is given as the ratio of occupied states $\left(q_{s}\right)$ to the vacant states at the metal/semiconductor interface. The electric field between the dipole layer formed at the metal/semiconductor interface can be modeled using the expression:

$E=\frac{e \times q_{S}}{\epsilon}$ 
When an electron moves across the dipole towards the surface, the energy level of the electron increases. The increase in energy can be attributed to the motion in the direction of electric field. The increase in energy level $\left(\Delta E_{q}\right)$ of the electron can be described as:

$\Delta E_{q}=-a b s(e \times E \times D)$

Where D is the dipole thickness as shown in Fig.2 (c). As the energy increases, the work involved in removing this electron from the surface to the free state (work function of the metal) also increases by the same amount.

$\Delta \phi_{m}=\Delta E_{q}$

Substituting equation (10) and (11) in equation (12):

$\Delta \phi_{m}($ in $V)=-e \times \frac{e \times q_{s}}{\epsilon}$

The change in metal work function is schematically presented through energy band shifts in Fig. 2 (b). The limiting reaction can be modeled taking the assumption that all the hydrogen atoms absorbed at the Pd metal surface finds adsorption sites at the interface $\left(q_{s}=H_{\text {surf }}\right)$. In this case the change in work function becomes:

$\Delta \phi_{\max }($ in $V)=-e \times \frac{e \times H_{\text {surf }}}{\epsilon}$

$\Delta \phi_{m}$ can be obtained by multiplying $\Delta \phi_{\max }$ with coverage $\theta$. Physical detection can be modelled if the total gas pressure $\left(P_{T}\right)$, molar concentration $\left(\mathrm{M}_{\mathrm{q}}\right)$ of the gas is known. The partial pressure of the gas can be evaluated as:

$P=P_{T} \times M_{q}$

$M_{q}=q_{s} /$ Atomic mass of hydrogen

The effective variation in schottky barrier height $\left(\Delta \phi_{S}\right)$ can also be expressed in terms of gas pressure and concentration as:

$\Delta \phi_{S}=\Delta \phi_{m}=M_{q}-\left[\left(\frac{R T}{4 F} \ln (P)\right)\right]$
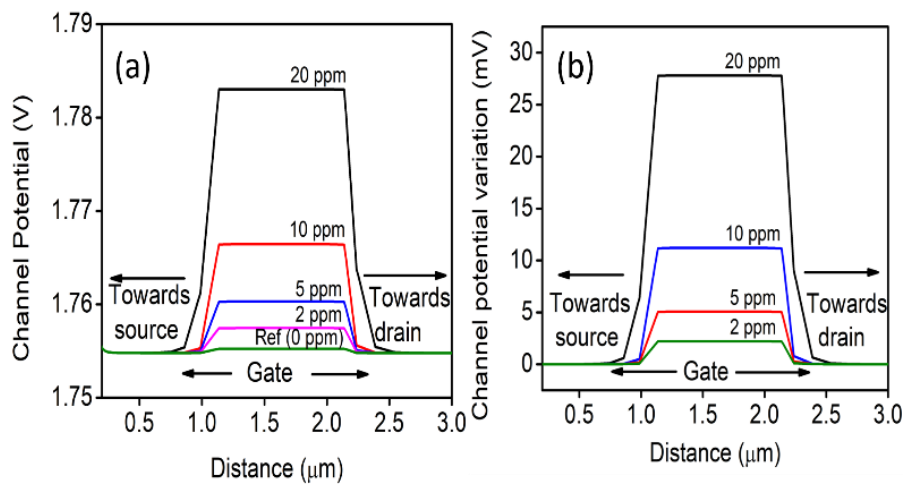

Fig. 3(a) Channel potential along the 2DEG, and (b) Variation in channel potential with gas concentration from TCAD simulation.
Where, $R, F$, and Tare the Gas constant, Faraday's constant, and the temperature respectively. The base partial pressure of gas used in this work is $2.5 \mathrm{~Pa}(\sim 0.018$ Torr), evaluation of which is described in $[29,30]$.The effective change in flat band voltage $\left(V_{f b}\right)$ can bedescribed as:

$V_{f b}=\phi_{m}-\phi_{S} \pm \Delta \phi_{m}$

The change in barrier height leads to a change in the flat band voltage which leads to an equivalent shift of the channel potential along the device 2DEG as shown in Fig. 3 (a). The channel potential variation (Channel potential-reference potential) shown in Fig. 3 (b) is due to capacitive coupling of surface charge variations to the 2DEG channel. This is the ideal case when all the $\mathrm{H}$ concentration reaching on the surface is assumed to be absorbed completely.

\section{HEMT GAS SENSOR MODEL}

The sensing current in the device can be expressed as:

$I_{D}+\Delta I_{D}=e \times\left(n_{s} \pm \Delta n_{s}\right) \times Z \times v(x)(19)$

Where $n_{s}$ is the 2DEG density, $\Delta n_{s}$ is the variation in 2DEG due to surface/interfacial adsorption of hydrogen gas. The variation in 2DEG density with gas adsorption can be evaluated as:

$\Delta n_{s}=\frac{\epsilon_{A l G a N}(m)}{e \times\left(t_{A l G a N}+\Delta d_{n s}\right)} \times \Delta V_{t h}$

Where $\Delta V_{t h}$ is the change in device threshold voltage due to the change in the schottky barrier height resulting from the hydrogen dipole formation due to the gas adsorption at surface and interface. The change in threshold voltage depends directly on $V_{f b}$ which depends on $\Delta \phi_{m}$. This variation in flat band voltage leads to an equivalent change in channel potential along the 2DEG channel formed at the hetero interface. Under steady state conditions, $\Delta V_{t h}=\frac{\Delta \phi_{m}}{e}$ (from equation 24: division by unit electron charge denotes conversion from $\mathrm{eV}$ to $\mathrm{V}$ ). Now the variation in $2 \mathrm{DEG}$ density becomes:

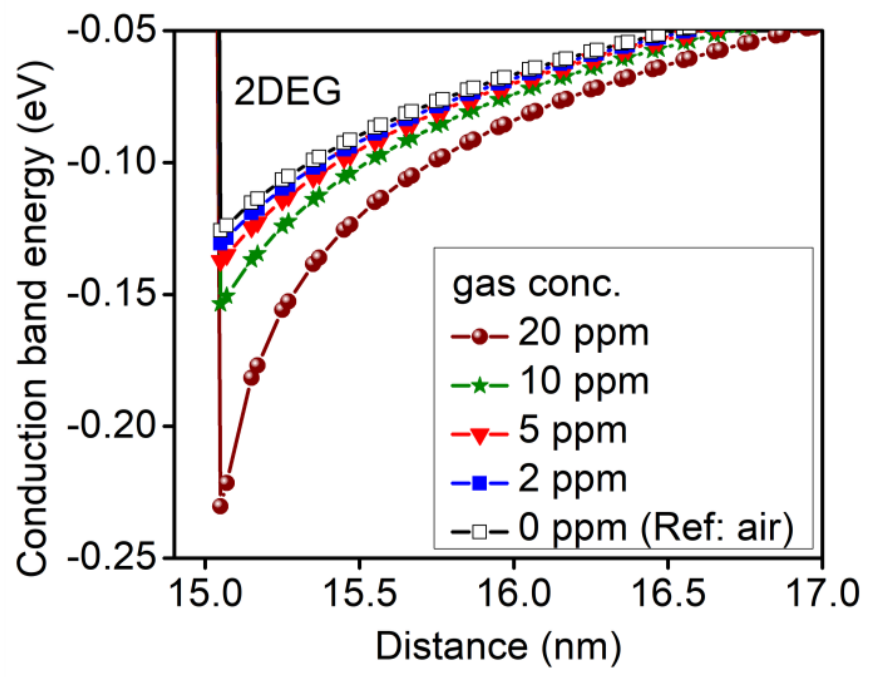

Fig. 4. Conduction band bending below the fermi level: deepening of 2DEG with increasing gas concentration. 
$\Delta n_{s}=\frac{\epsilon_{A l G a N}(m)}{e \times\left(t_{A l G a N}+\Delta d_{n s}\right)} \times \frac{\Delta \phi_{m}}{e}(21)$

Substituting eq. (17) in (21):

$\Delta n_{s}=\frac{\epsilon_{A l G a N}(m)}{e \times\left(t_{A l G a N}+\Delta d_{n s}\right)} \times \frac{M_{q}-\left[\left(\frac{R T}{4 F} \ln (P)\right)\right]}{e}$

This variation in $2 \mathrm{DEG}$ density with varying gas concentration is plotted in terms of $\mathrm{CB}$ (conduction band) bending in Fig. 4.

$V_{t h}=\phi_{S}-\left(\Delta E_{c A l G a N}(m)+\frac{q^{2}}{\epsilon_{A l G a N}(m)} \sigma_{A l N}{ }^{2} t_{A l N}\right)-\frac{\sigma}{\epsilon_{A l G a N}(m)}\left(t_{A l G a N}+t_{A l N}+\Delta d_{n s}\right)$

$V_{t h} \pm \Delta V_{t h}=\frac{\phi_{m} \pm \Delta \phi_{m}}{e}-V_{f b}-\left(\Delta E_{c A l G a N}(m)+\frac{q^{2}}{\epsilon_{A l G a N}(m)} \sigma_{A l N}^{2} t_{A l N}\right)-\frac{\sigma}{\epsilon_{A l G a N}(m)}\left(t_{A l G a N}+t_{A l N}+\Delta d_{n s}\right)$

$V_{t h} \pm \Delta V_{t h}=\frac{\phi_{m} \pm M_{q}-\left[\left(\frac{R T}{4 F} \ln (P)\right)\right]}{e}-V_{f b}-\left(\Delta E_{c A l G a N}(m)+\frac{q^{2}}{\epsilon_{A l G a N}(m)} \sigma_{A l N}^{2} t_{A l N}\right)-\frac{\sigma}{\epsilon_{A l G a N}(m)}\left(t_{A l G a N}+t_{A l N}+\Delta d_{n s}\right)$

$\Delta I_{D}=e \times\left(\frac{\epsilon_{A l G a N}(m)}{e \times\left(t_{A l G a N}+\Delta d_{n S}\right)} \times \frac{M_{q}-\left[\left(\frac{R T}{4 F} \ln (P)\right)\right]}{e}\right) \times Z \times \frac{v_{S} E(x)}{\sqrt{E^{2}(x)+\left(\frac{v_{S}}{\mu}\right)^{2}}}$

$I_{D} \pm \Delta I_{D}=e \times \frac{\epsilon_{A l G a N}(m)}{d_{e f f}}\left(V_{G S}-\left(\emptyset_{S}+\frac{E_{F}-\left(\Delta E_{C A l G a N}(m)+\frac{q^{2}}{\epsilon_{A l G a N}(m)} \sigma_{A l N}{ }^{2} t_{A l N}\right)}{q}+V_{c h}(x)-\frac{M_{q}-\left[\left(\frac{R T}{4 F} \ln (P)\right)\right]}{e}\right)\right) Z \frac{v_{S} E(x)}{\sqrt{\left(E^{2}(x)+\left(\frac{v_{S}}{\mu_{0}}\right)^{2}\right)}}$

$\%$ Sensitivity $=\frac{\Delta I_{D}}{I_{D}} X 100 \%$

This band diagram shows the deepening of 2DEG at the heterointerface plotted using BLAZE interface in SILVACO ATLAS TCAD. The threshold voltage shift for undoped HEMT sensor can be expressed as equation (23). Substituting eq. (18) in (23), the threshold voltage after the device is exposed to gas for detection is given by (24). Expanding eq. (24) using eq. (17) gives eq. (25)Substituting eq. (22) in (19), the sensing currents in the device becomes eq. (26) and the total current is given by eq. (27). The \% sensitivity of the sensor can be evaluated as:

\section{Results and Discussion}

The sensor design presented here gives enhanced detection capabilities over existing HEMT based gas detectors and the model perfectly demonstrates the sensor behavior unlike the existing models. A detailed discussion on sensitivities and the strengths of the model developed here are presented in this section.

\section{A. Sensitivity Analysis}

Drain current is used as the sensing metric whose value varies with the 2DEG density. The variation in drain current can be attributed to the variation in drain conductance $\left(\mathrm{g}_{\mathrm{d}}\right)$.

$$
\Delta I_{D}=g_{d} * \Delta V_{D S}
$$

The increase in drain conductance with gas adsorption is presented in Fig. 5 (a). This increase is $g_{d}$ is due to the diminution of HEMT resistance to the current flow mostly in the linear region.

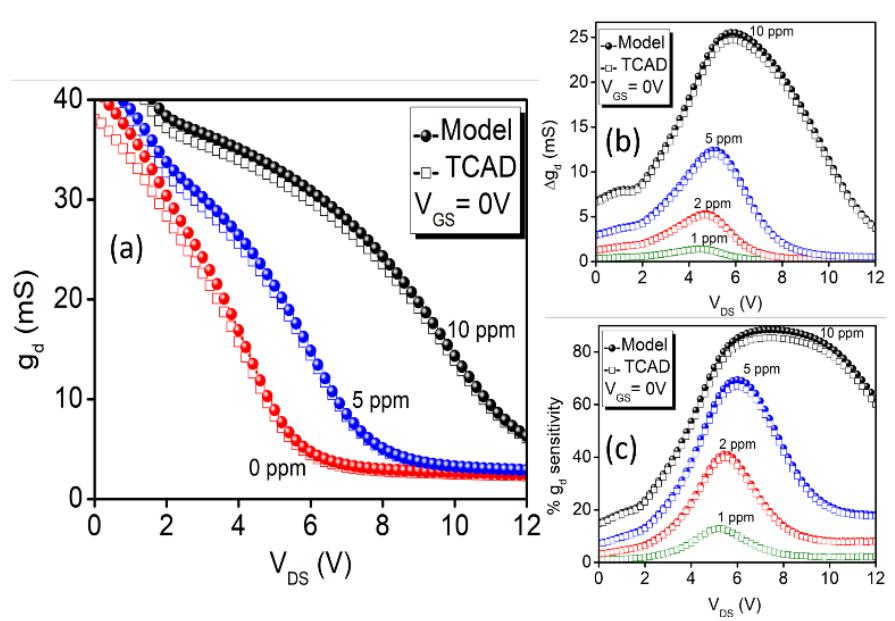

Fig. 5. (a). Device conductance for varying gas concentrations, (b). Variation in conductance, (c). $\% g_{d}$ sensitivity

The reason for this decrease is the capacitive coupling of the surface charge/potential variations due to adsorption of hydrogen gas. The channel conductance can also be employed as a sensing metric. The \% sensitivity plotted as Fig. 5 (c) can be expressed in terms of channel conductance as the ratio of variation in conductance to the reference conductance (when no gas is applied). Dealt with here is formation of a monolayer of hydrogen gas leading to dipole formation and varying the device currents. In real time scenario, there would be multiple layers of gas that can lead to even higher values of current 
changes. Sensing currents, the effective variation in drain current is presented in Fig. 6 (b) as $\Delta I_{D}$.

$\Delta I_{D}=I_{D_{g a s}}-I_{D_{\text {ref }}}$
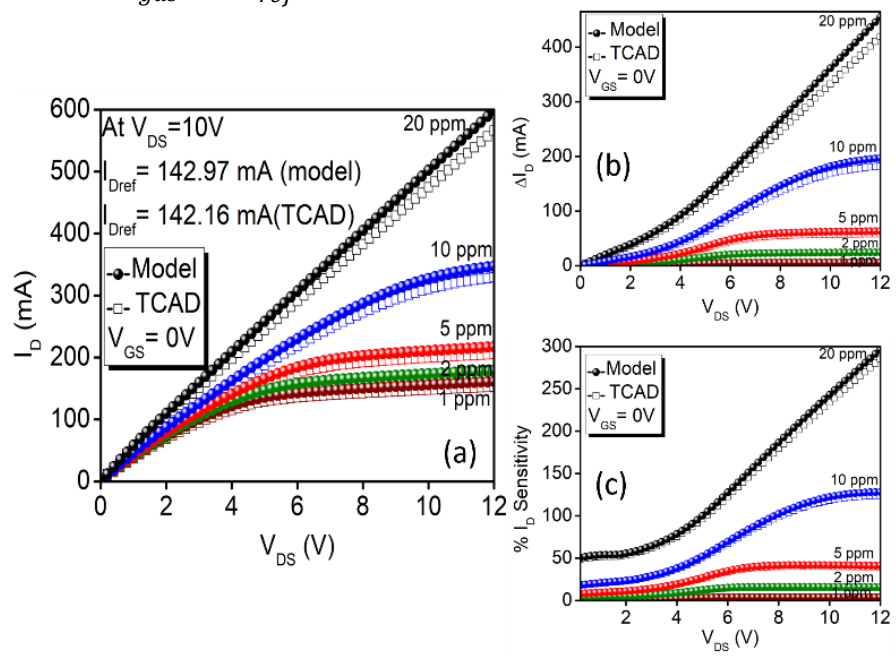

Fig. 6 (a). Increasing drain currents with gas concentration, (b). Drain current variation w.r.t to reference current, (c). Normalized drain current sensitivity

Where $I_{D_{g a s}}$ is the drain current for various gas concentrations and $I_{D_{r e f}}$ is the device reference current when no gas is applied. The device sensitivities obtained here areas shown in Fig. 6 (c). Percentile sensitivity increases with drain bias in the linear region and saturates along with the drain current as shown in Fig. 6 (c). This makes the device yield its best performance when operated at drain biases of $7 \mathrm{~V}$ and above.

$\%$ Sensitivity $=\frac{I_{D_{\text {gas }}}-I_{D_{\text {ref }}}}{I_{\text {Dref }}} X 100 \%$

Evaluation of time dependent stability is however impossible through this model developed. Further in real time detection, there can be unwanted adsorptions and blocking of the adsorption sites and uneven distribution of gas molecules in the test gas mixture that can reduce the sensitivities.

\section{B. Detection range}

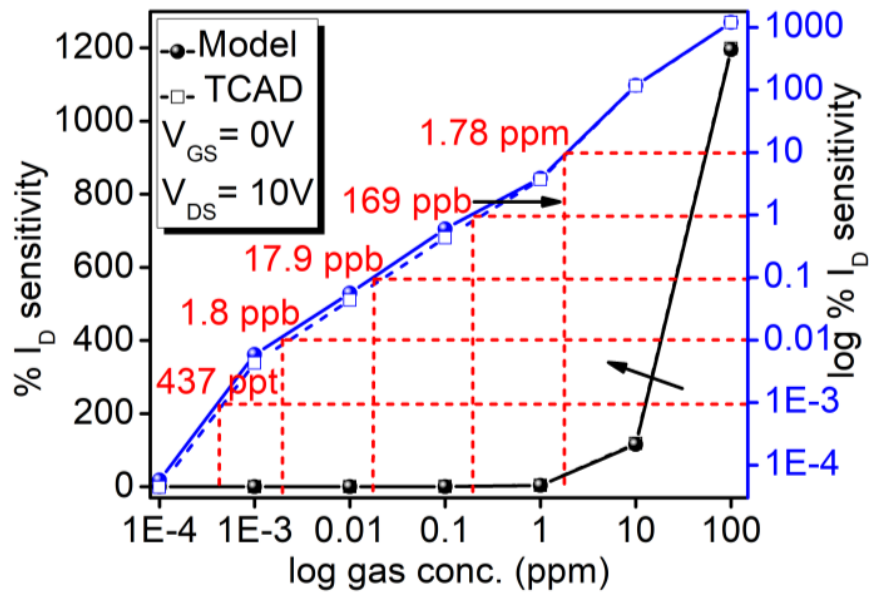

Fig. 7 Sensing response and detection limit
The increase in current with $100 \mathrm{ppt}$ (parts per trillion) hydrogen gas was found to be $21 \mathrm{nA}$. The detection limit here is thus not limited to ppm and ppb ranges, instead very minute concentrations of hydrogen can be measured using the device. The normalized drain current variations observed are in $0.0024 \%, 0.43 \%$, and $1.22 \times 10^{3} \%$ for gas concentrations of 100 ppt, 100ppb and $100 \mathrm{ppm}$ respectively. $1 \%$ sensing response was obtained at $169 \mathrm{ppb}$, this is taken as the detection limit in this work. The response presented here is for the formation of a monolayer of hydrogen on the sensing surface. The physical detection levels will be even higher than the detection limits presented here owing to large volume of hydrogen gas interacting with the sensing interface.

\section{Comparison with Existing sensors}

The existing sensors in literature though attain very high sensitivities using nanoparticles and patterned gate to increase the sensing area, has poor detection limits [31-39]. This limitation arises since the underlying device design and the heart of operation of the sensor (2DEG in case of HEMT) is given little focus compared to the interest laid in improving the sensing area. They focus on improving the sensitivities through engineering the sensing area instead of focusing on improving the sensing performance metrics such as $I_{D}$ and $g_{m}$. All the sensors in literature have poor device transconductance which adversely affects the sensor response. Having better device characteristics can make the device achieve higher sensitivities. So, using this model developed can aid in designing sensors with higher resolution achieving higher sensitivities without compromising the detection limit. The device presented here achieves high sensitivities like the latest Pt gated HEMT presented in [31] with lower detection limits even without patterning or use of graphene. The sensing performance and detection limits of existing hydrogen sensors are summarized in Table II. The performance can be further improved by using a patterned gate that will help in increasing the area for sensing. The sensing response in Fig. 7 shows that the device can be used in sub-ppm sensing expecting an output current variation in $\mu \mathrm{A}$ 's.

\section{CONCLUSION}

Hydrogen sensing capability of Pd gated AlGaN/AlN/GaN HEMT has been analyzed by developing a mathematical model and using simulation methods. A systematic study is presented from the formation of dipole layer at the sensing interface to the impact of surface adsorption on the channel 2DEG, device conductance and the internal channel potential. The device presented here using an AlN interlayer showcases enhanced sensitivities over conventional GaN and GaAs HEMTs, diodes, nanotubes and nanowire-based sensors even without using a patterned gate. The sensitivities can be improved further using gate patterning as it increases the sensing area. The exhibited sensitivities are $3.88 \%, 118.252 \%$ and $1.22 \times 10^{3} \%$ for $1 \mathrm{ppm}$, $10 \mathrm{ppm}$ and $100 \mathrm{ppm}$ respectively. These high sensitivities are attained without compromising the device detection limits. The increase in device current in response for $1 \mathrm{ppb}$ hydrogen is 3.41 $\mu \mathrm{A}$. 
TABLE II

COMPARISON WITH EXISTING HYDROGEN SENSORS

\begin{tabular}{|c|c|c|c|c|c|c|c|c|}
\hline $\begin{array}{l}\text { Year } \\
\text { [Ref] }\end{array}$ & Sensing area & Temp & $\begin{array}{l}\text { Material } \\
\text { system }\end{array}$ & Device & Sensing metric & $\begin{array}{l}\text { Conc. } \\
(\mathrm{ppm})\end{array}$ & Sensitivity & Detection limit \\
\hline \multirow{2}{*}{$\begin{array}{l}2021 \\
{[31]}\end{array}$} & \multirow{2}{*}{$\begin{array}{l}\text { Pt gate } \\
\text { Pt decorated } \\
\text { graphene }\end{array}$} & \multirow[b]{2}{*}{$\mathrm{RT}$} & \multirow[b]{2}{*}{$\mathrm{AlGaN} / \mathrm{GaN}$} & \multirow[b]{2}{*}{ MIS-HEMT } & \multirow[b]{2}{*}{ Current } & \multirow[b]{2}{*}{1000} & $1.2 \times 10^{3}$ & \multirow[b]{2}{*}{$1 \mathrm{ppm}$} \\
\hline & & & & & & & $1.6 \times 10^{7}$ & \\
\hline $\begin{array}{l}2020 \\
{[32]}\end{array}$ & $\mathrm{Pt}$ & RT & $\mathrm{AlGaN} / \mathrm{GaN}$ & HEMT & Current & 300 & $145.8 \%$ & $10 \mathrm{ppm}$ \\
\hline $\begin{array}{l}2017 \\
{[33]}\end{array}$ & $\mathrm{Pt}$ & RT & $\mathrm{AlGaN} / \mathrm{GaN}$ & $\begin{array}{l}\text { Schottky } \\
\text { diode }\end{array}$ & Current & 500 & $2.8 \times 10^{5 \%}$ & $100 \mathrm{ppm}$ \\
\hline $\begin{array}{l}2018 \\
{[34]}\end{array}$ & Pd NP & RT & $\mathrm{GaO} / \mathrm{GaN}$ & MOS diode & Current & 10000 & $1.24 \times 10^{7} \%$ & $1 \mathrm{ppm}$ \\
\hline $\begin{array}{l}2020 \\
{[35]}\end{array}$ & $\mathrm{Pt} N \mathrm{NP}$ & $200^{\circ} \mathrm{C}$ & $\mathrm{WO}_{3}$ & Thin film & Current & 10000 & $1.41 \times 10^{6 \%}$ & $1 \mathrm{ppm}$ \\
\hline $\begin{array}{l}2019 \\
{[36]}\end{array}$ & $\mathrm{Au}$ & $\mathrm{RT}$ & $\mathrm{ZnO}$ & $\begin{array}{l}\begin{array}{l}\text { Schottky } \\
\text { diode }\end{array} \\
\text { dis }\end{array}$ & Current & 1000 & $144 \%$ & $1 \mathrm{ppm}$ \\
\hline $\begin{array}{l}2018 \\
{[37]} \\
\end{array}$ & Carbon & RT & CNT & NT & Current & 311 & $\sim 1500 \%$ & $899 \mathrm{ppb}$ \\
\hline $\begin{array}{l}2012 \\
{[38]} \\
\end{array}$ & $\mathrm{Pt} N \mathrm{NP}$ & RT & $\mathrm{TiO}_{2} / \mathrm{GaN}$ & Nanowires & Current & 1 & $4 \%$ & $\begin{array}{l}100 \mathrm{ppb}: \\
1 \% \text { sensitivity }\end{array}$ \\
\hline $\begin{array}{l}2019 \\
{[39]}\end{array}$ & $\mathrm{Ag}$ & $175^{\circ} \mathrm{C}$ & $\mathrm{ZnO} / \mathrm{Si}$ & MSM & Current & 40000 & $83.2 \%$ & -- \\
\hline $\begin{array}{l}2018 \\
{[40]} \\
\end{array}$ & $\mathrm{Pd}$ & RT & $\mathrm{TiO} 2 / \mathrm{Si}$ & MOS sensor & Conductance & 10000 & $70 \%$ & -- \\
\hline $\begin{array}{l}2007 \\
{[41]} \\
\end{array}$ & $\mathrm{Pd}$ & RT & $\mathrm{AlGaAs} / \mathrm{GaAs}$ & HEMT & $g_{d}$ & 9970 & $25.1 \mathrm{mS} / \mathrm{mm}$ & Few ppm \\
\hline \multirow[b]{2}{*}{$\begin{array}{l}\text { This } \\
\text { work }\end{array}$} & \multirow[b]{2}{*}{$\mathrm{Pd}$} & \multirow[b]{2}{*}{$\mathrm{RT}$} & \multirow[b]{2}{*}{$\mathrm{AlGaN} / \mathrm{GaN}$} & \multirow[b]{2}{*}{ HEMT } & $g_{d}$ & $\begin{array}{l}5 \\
10 \\
\end{array}$ & $\begin{array}{l}32.5 \mathrm{mS} / \mathrm{mm} \\
145.4 \mathrm{mS} / \mathrm{mm}\end{array}$ & \multirow{2}{*}{$\begin{array}{l}169 \text { ppb: } 1 \% \\
\text { sensitivity } \\
437 \text { ppt: } 0.001 \% \\
\text { sensitivity } \\
34.2 \mu \mathrm{A}(\Delta \mathrm{I} \text { ) for } 1 \\
\text { ppb }\end{array}$} \\
\hline & & & & & Current & $\begin{array}{l}0.01 \\
1 \\
10 \\
100\end{array}$ & $\begin{array}{l}0.0043 \\
3.88 \% \\
118.252 \% \\
1.22 \times 10^{3} \%\end{array}$ & \\
\hline
\end{tabular}

NP: Nanoparticles, NT: Nanotubes, CNT: Carbon nanotubes, MIS-HEMT: Metal insulator semiconductor- High Electron Mobility Transistor, RT: Room Temperature, MSM: Metal Semiconductor Metal, MOS: Metal Oxide Semiconductor

\section{APPENDIX}

TABLE III

CONSTANTS AND COEFFICIENTS USED IN SIMULATION

\begin{tabular}{|c|c|c|}
\hline \hline Symbol & Parameter/Expression & Value \\
\hline$\phi_{m}$ & Work function of Pd gate & $5.22 \mathrm{eV}$ \\
$X_{A l G a N}$ & Affinity of AlGaN & $3.82 \mathrm{eV}$ \\
$\mathrm{AN}_{1}, \mathrm{AN}_{2}$ & & $2.52 \times 10^{8}$ \\
$\mathrm{BN}_{1}, \mathrm{BN}_{2}$ & Impact Ionization & $3.41 \times 10^{7}$ \\
$\mathrm{AP}_{1}, \mathrm{AP}_{2}$ & Coefficients for GaN and & $5.37 \times 10^{6}$ \\
$\mathrm{BP}_{1}, \mathrm{BP} 2$ & AlN & $1.97 \times 10^{7}$ \\
$\mathrm{BETAN}_{2} \mathrm{P}$ & & 1 \\
PSP.SCALE & Spontaneous polarization & 0.75 \\
PIEZO.SCALE & Piezoelectric polarization & 0.75 \\
$\varepsilon_{\text {dipole }}$ & Dipole permittivity & 2.25 \\
$\varepsilon_{\mathrm{GaN}}$ & GaN permittivity & 9.5 \\
$\mathrm{~L}_{\mathrm{G}}$ & Gate length & $1 \mu \mathrm{m}$ \\
$\mathrm{Z}$ & Gate width & $100 \mu \mathrm{m}$ \\
-- & Dipole layer thickness & $1 \mathrm{~nm}$ \\
& & \\
\hline
\end{tabular}

The device parameters including the constants and coefficients used in simulation and modeling are same as in HEMT based biosensor presented in [10]. The constants and coefficients used in modeling the gas sensing are presented in the Table III. The models used are conmob, gansat, auger, srh, albrct, and selbeherr.

\section{REFERENCES}

[1]. M. Fleischer, "Advances in application potential of adsorptive-type solid state gas sensors: high-temperature semiconducting oxides and ambient temperature GasFET devices," Meas. Sci. Technology, 19 (2008) 042001.

[2]. I. Lundström, M. S. Shivaraman, and C. Svensson, "A hydrogensensitive Pd-gate MOS transistor," J. Appl. Phys., vol. 46, pp. 38763881, 1975.

[3]. J. Schalwig, G. Müller, M. Eickhoff, O. Ambacher, and M. Stutzmann, "Gas sensitive GaN/AlGaN-heterostructures," Sens. Actuators B: Chem., 87 (2002) pp. 425-430.

[4]. C. Bishop, Y. Halfaya, A. Soltani, S. Sundaram, X. Li, J. Streque, Y. El Gmili, P. L. Voss, J. P. Salvestrini, A. Ougazzaden, "Experimental study and device design of $\mathrm{NO}, \mathrm{NO} 2$, and $\mathrm{NH} 3$ gas detection for a wide dynamic and large Temperature Range Using $\mathrm{Pt} / \mathrm{AlGaN} / \mathrm{GaN}$ HEMT Gas sensitive GaN/AlGaNheterostructures," IEEE Sensors J., vol. 16, no. 18, pp. 6828-6838, September 2016.

[5]. Halfaya, Y., Bishop, C., Soltani, A., Sundaram, S., Aubry, V., Voss, P.L., Salvestrini, J.P. and Ougazzaden, A., 2016. Investigation of the performance of HEMT-based NO, NO2 and NH3 exhaust gas sensors for automotive antipollution systems. Sensors, 16(3), p.273.

[6]. Schalwig, J., Müller, G., Eickhoff, M., Ambacher, O. and Stutzmann, M., 2002. Gas sensitive GaN/AlGaNheterostructures. Sensors and Actuators B: Chemical, 87(3), pp. $425-430$.

[7]. Wang, X.H., Wang, X.L., Feng, C., Yang, C.B., Wang, B.Z., Ran, J.X., Xiao, H.L., Wang, C.M. and Wang, J.X., 2008. Hydrogen sensors based on AlGaN/AlN/GaN HEMT. Microelectronics Journal, 39(1), pp.20-23. 
[8]. Zhang, J., Sokolovskij, R., Chen, G., Zhu, Y., Qi, Y., Lin, X., Li, W., Zhang, G.Q., Jiang, Y.L. and Yu, H., 2019. Impact of high temperature $\mathrm{H} 2$ pre-treatment on Pt-AlGaN/GaN HEMT sensor for H2S detection. Sensors and Actuators B: Chemical, 280, pp.138143.

[9]. O. Ambacher, J. Smart, J. R. Shealy, N. G. Weimann, K. Chu, M. Murphy, W. J. Schaff, and L. F. Eastman, "Two-dimensional electron gases induced by spontaneous and piezoelectric polarization charges in $\mathrm{N}-$ and Ga-face AlGaN/GaN heterostructures," J. Appl. Phys., vol. 85, no. 6, pp. 3222-3233, Mar. 1999.

[10]. Varghese, A., Periasamy, C. and Bhargava, L., 2018. Analytical modeling and simulation-based investigation of $\mathrm{AlGaN} / \mathrm{AlN} / \mathrm{GaN}$ Bio-HEMT sensor for C-erbB-2 detection. IEEE Sensors Journal, 18(23), pp.9595-9603.

[11]. Varghese, A., Periasamy, C., Bhargava, L., Dolmanan, S.B. and Tripathy, S., 2020. Fabrication and Modeling based Performance Analysis of Circular GaN MOSHEMT based Electrochemical Sensors. IEEE Sensors Journal.

[12]. Pal, P., Pratap, Y., Gupta, M. and Kabra, S., 2018. Modeling and simulation of AlGaN/GaN MOS-HEMT for biosensor applications. IEEE Sensors Journal, 19(2), pp.587-593.

[13]. F. M. Yigletu, S. Khandelwal, T. A. Fjeldly, and B. Iñiguez, "Compact charge-based physical models for current and capacitances in AlGaN/GaN HEMTs" IEEE Trans. Electron Devices, vol. 60, no. 11, pp. 3746-3752, Nov. 2013.

[14]. Seo, H., Endoh, T., Fukuda, H. and Nomura, S., 1997. Highly sensitive MOSFET gas sensors with porous platinum gate electrode. Electronics letters, 33(6), pp.535-536.

[15]. Spetz, A., Armgarth, M. and Lundström, I., 1988. Hydrogen and ammonia response of metal-silicon dioxide-silicon structures with thin platinum gates. Journal of applied physics, 64(3), pp.12741283.

[16]. Poteat, T.L. and Lalevic, B., 1982. Transition metal-gate MOS gaseous detectors. IEEE Transactions on Electron Devices, 29(1), pp.123-129.

[17]. Sayago, I., Terrado, E., Lafuente, E., Horrillo, M.C., Maser, W.K., Benito, A.M., Navarro, R., Urriolabeitia, E.P., Martinez, M.T. and Gutierrez, J., 2005. Hydrogen sensors based on carbon nanotubes thin films. Synthetic Metals, 148(1), pp.15-19.

[18]. Ghasempour, R., 2009. Hybrid multiwalled carbon nanotubes and trioxide tungsten nanoparticles for hydrogen gas sensing. Journal of Physics D: Applied Physics, 42(16), p.165105.

[19]. Kaniyoor, A., Jafri, R.I., Arockiadoss, T. and Ramaprabhu, S., 2009. Nanostructured Pt decorated graphene and multi walled carbon nanotube based room temperature hydrogen gas sensor. Nanoscale, 1(3), pp.382-386.

[20]. Xie, G., Yu, J., Chen, X. and Jiang, Y., 2007. Gas sensing characteristics of WO3 vacuum deposited thin films. Sensors and Actuators B: Chemical, 123(2), pp.909-914.

[21]. Singh, R.C., Singh, M.P., Singh, O. and Chandi, P.S., 2009. Influence of synthesis and calcination temperatures on particle size and ethanol sensing behaviour of chemically synthesized $\mathrm{SnO} 2$ nanostructures. Sensors and Actuators B: Chemical, 143(1), pp.226-232.

[22]. Wan, Q., Li, Q.H., Chen, Y.J., Wang, T.H., He, X.L., Li, J.P. and Lin, C.L., 2004. Fabrication and ethanol sensing characteristics of $\mathrm{ZnO}$ nanowire gas sensors. Applied Physics Letters, 84(18), pp.3654-3656.

[23]. Varghese, A., Periasamy, C., Bhargava, L. and Vijayakumar, K., 2018. Impact of AlN interlayer's in epitaxial and passivation scheme on the DC and microwave performance of doping-less GaN HEMT. Journal of Nanoelectronics and Optoelectronics, 13(7), pp.971-979.

[24]. A. Varghese, P. Chinnamuthan and L. Bhargava, "Fabrication and pH-Sensitivity Analysis of MOS-HEMT Dimensional Variants for Bio-Sensing Applications," in IEEE Transactions on NanoBioscience, vol. 20, no. 1, pp. 28-34, Jan. 2021

[25]. Hughes, C., Yeh, L.H. and Qian, S., 2013. Field effect modulation of surface charge property and electroosmotic flow in a nanochannel: Stern layer effect. The Journal of Physical Chemistry C, 117(18), pp.9322-9331.

[26]. Choi, S., Mo, H.S., Kim, J., Kim, S., Lee, S.M., Choi, S.J., Kim, D.M., Park, D.W. and Kim, D.H., 2020. Experimental extraction of stern-layer capacitance in biosensor detection using silicon nanowire field-effect transistors. Current Applied Physics, 20(6), pp.828-833.

[27]. S. M. Sze and K. K. Ng, Physics of Semiconductor Devices, 2nd ed. Hoboken, NJ, USA: Wiley, 1981.

[28]. Safari, M., Gholizadeh, M. and Salehi, A., 2009. Modeling and simulation of a MOSFET gas sensor with platinum gate for hydrogen gas detection. Sensors and Actuators B: Chemical, 141(1), pp.1-6.

[29]. Fogler, H.S., 2010. Essentials of Chemical Reaction Engineering: EssentiChemicaReactioEngi. Pearson Education.

[30]. J. Fogelberg, M.Eriksson, H.Dannetun, L.-G. Petersson, Kinetic modeling ofhydrogen adsorption/absorption in thin films on hydrogen-sensitive field-effectdevices: observation of large hydrogen-induced dipoles at the $\mathrm{Pt}-\mathrm{SiO} 2$ interface,Journal of Applied Physics 78 (2) (1995) 988-996.

[31]. Ahn, J., Kim, D., Park, K.H., Yoo, G. and Heo, J., 2021. PtDecorated Graphene Gate AlGaN/GaN MIS-HEMT for Ultrahigh Sensitive Hydrogen Gas Detection. IEEE Transactions on Electron Devices, 68(3), pp.1255-1261.

[32]. Sokolovskij, R., Zhang, J., Zheng, H., Li, W., Jiang, Y., Yang, G., Yu, H., Sarro, P.M. and Zhang, G., 2020. The Impact of Gate Recess on the $\mathrm{H}_{2}$ Detection Properties of Pt-AlGaN/GaN HEMT Sensors. IEEE Sensors Journal, 20(16), pp.8947-8955.

[33]. Jung, S., Baik, K.H., Ren, F., Pearton, S.J. and Jang, S., 2017. PtAlGaN/GaN hydrogen sensor with water-blocking PMMA layer. IEEE Electron Device Letters, 38(5), pp.657-660.

[34]. Ke, B.Y. and Liu, W.C., 2018. Enhancement of hydrogen sensing performance of a Pd nanoparticle/Pd film $/ \mathrm{GaO}$ x/GaN-based metaloxide-semiconductor diode. IEEE Transactions on Electron Devices, 65(10), pp.4577-4584.

[35]. Chang, C.H., Chou, T.C., Chen, W.C., Niu, J.S., Lin, K.W., Cheng, S.Y., Tsai, J.H. and Liu, W.C., 2020. Study of a WO3 thin film based hydrogen gas sensor decorated with platinum nanoparticles. Sensors and Actuators B: Chemical, 317, p.128145.

[36]. Rajan, L., Periasamy, C. and Sahula, V., 2019. An In-Depth Study on Electrical and Hydrogen Sensing Characteristics of $\mathrm{ZnO}$ Thin Film With Radio Frequency Sputtered Gold Schottky Contacts. IEEE Sensors Journal, 19(9), pp.3232-3239.

[37]. Xiao, M., Liang, S., Han, J., Zhong, D., Liu, J., Zhang, Z. and Peng, L., 2018. Batch fabrication of ultrasensitive carbon nanotube hydrogen sensors with sub-ppm detection limit. ACS sensors, 3(4), pp.749-756.

[38]. Aluri, G.S., Motayed, A., Davydov, A.V., Oleshko, V.P., Bertness, K.A., Sanford, N.A. and Mulpuri, R.V., 2012. Methanol, ethanol and hydrogen sensing using metal oxide and metal (TiO2-Pt) composite nanoclusters on $\mathrm{GaN}$ nanowires: a new route towards tailoring the selectivity of nanowire/nanocluster chemical sensors. Nanotechnology, 23(17), p.175501.

[39]. Ratan, S., Kumar, C., Kumar, A., Jarwal, D.K., Mishra, A.K., Upadhyay, R.K. and Jit, S., 2019. Fabrication and characterization of a $\mathrm{ZnO}$ quantum dots-based metal-semiconductor-metal sensor for hydrogen gas. Nanotechnology, 30(39), p.395501.

[40]. Ratan, S., Kumar, C., Kumar, A., Jarwal, D.K., Mishra, A.K. and Jit, S., 2018. Fabrication and characterization of titanium dioxide based $\mathrm{Pd} / \mathrm{TiO} 2 / \mathrm{Si}$ MOS sensor for hydrogen gas. IEEE Sensors Journal, 18(10), pp.3952-3959.

[41]. C. W. Hung et al., "Hydrogen Sensing Characteristics of a Pd/GaAs Semiconductor Transistor-Type Sensor," TRANSDUCERS 2007 2007 International Solid-State Sensors, Actuators and Microsystems Conference, Lyon, France, 2007, pp. 2043-2046. 


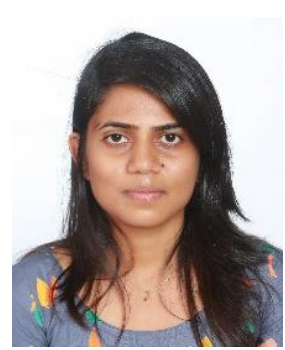

Arathy Varghese received her B.Tech degree in Electronics and Communication Engineering from Kerala University, India, in 2013, M.Tech degree in VLSI and Embedded System from the Mahatma Gandhi University, Kerala, India, in 2015, and PhD degree in Electronics and Communication Engineering from Malaviya National Institute of Technology Jaipur, Rajasthan, India, in 2020. She is currently working as Research Associate with the School of Engineering, Cardiff University, Wales, U.K. Her research interests include simulation and modeling of semiconductor devices, and development of micro and nano electronic devices for high power, high frequency, and sensing applications.

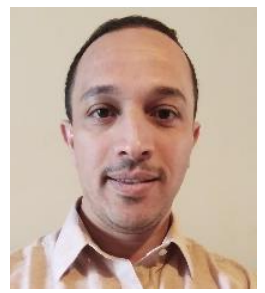

Abdalla Eblabla received the B.S. degree in communication engineering from Misurata University, Misurata, Libya, in 2008, the M.S. degree in electronics and electrical engineering from the University of Glasgow, Glasgow, U.K., in 2012, and the $\mathrm{PhD}$ degree in electronics and electrical engineering from the University of Glasgow, Glasgow, U.K., in 2018.

$\mathrm{He}$ is currently a Research Associate with the School of Engineering, Cardiff University, Cardiff, U.K. His research interests include design, fabrication, and characterization of microwave and millimeter wave components and circuit design.

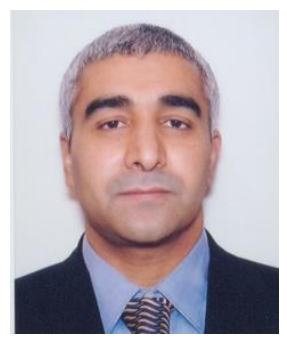

Khaled Elgaid received his B.Sc. from University of Evansville, USA, M.Sc. from Marshall University, USA, M.Sc. from The University of Cincinnati, USA, and Ph.D. from The University of Glasgow, UK. He is currently holding a Professor post at Cardiff University, UK, leading a High-Speed Integrated Electronics Technology research team in compound semiconductor with a focus on GaN and emphasises in high data rate telecommunications, sensors and radar applications. He has more than 25 years' experience in micro and nano technology for developing integrated electronic active and passive devices and MMIC technology with frequencies operating up to $\mathrm{THz}$. 